3-8-2002

\title{
Controlling Nucleation and Growth of Nanodroplets in Supersonic Nozzles
}

Kiril A. Streletzky

Cleveland State University, K.STRELETZKY@csuohio.edu

Yury Zvinevich

Worcester Polytechnic Institute

Barbara E. Wyslouzil

Worcester Polytechnic Institute, barbaraw@wpi.edu

Reinhard Strey

University of Cologne

Follow this and additional works at: https://engagedscholarship.csuohio.edu/sciphysics_facpub

Part of the Physics Commons

How does access to this work benefit you? Let us know!

Publisher's Statement

(c) 2002 American Institute of Physics.

\section{Repository Citation}

Streletzky, Kiril A.; Zvinevich, Yury; Wyslouzil, Barbara E.; and Strey, Reinhard, "Controlling Nucleation and Growth of Nanodroplets in Supersonic Nozzles" (2002). Physics Faculty Publications. 262.

https://engagedscholarship.csuohio.edu/sciphysics_facpub/262

This Article is brought to you for free and open access by the Physics Department at EngagedScholarship@CSU. It has been accepted for inclusion in Physics Faculty Publications by an authorized administrator of

EngagedScholarship@CSU. For more information, please contact library.es@csuohio.edu. 


\title{
SMALL-ANGLE NEUTRON SCATTERING OF SOOT FORMED IN LAMINAR PREMIXED ETHYLENE FLAMES
}

\author{
HAI WANG，BIN ZHAO，BARBARA WYSLOUZIL AND KIRIL STRELETZKY
}

\begin{abstract}
We used small-angle neutron scattering (SANS) to measure soot development in one-dimensional, laminar premixed flames. Scattering spectra were collected for two sooting ethylene/oxygen/argon flames at six positions above the burner surface. A detailed analysis of the scattering signals yielded the basic properties of the soot size distributions as a function of position. The experiments demonstrate that SANS can be used to extract spatially resolved, quantitative information about incipient soot formation and growth with better particle size resolution than light scattering and extinction.
\end{abstract}

\section{Introduction}

Progress in our understanding of the processes of soot formation beyond particle inception [1-4] has largely been driven by advances in laser techniques, most notably laser light extinction and scattering [5] and laser-induced incandescence (LII) [6-8]. In spite of these advances, there are still many unresolved issues regarding the mechanism and kinetics of soot formation, especially during soot inception. In particular, the detailed mechanisms responsible for soot formation and the dynamics of the process remain somewhat uncertain. A major barrier to developing a rigorous description of the chemistry and physics of soot inception is our inability to characterize and quantify particles of sizes smaller than $10 \mathrm{~nm}$ in flames.

Small-angle neutron scattering (SANS) and smallangle X-ray scattering (SAXS) are two powerful, complementary tools for examining the structure of matter in the $1-100 \mathrm{~nm}$ range. Both have been widely used to characterize complex fluids such as microemulsions $[9,10]$ and polymer solutions $[11,12]$. Recently, Wyslouzil et al. $[13,14]$ used SANS experiments to measure the particle size distributions of heavy water aerosols formed in a supersonic nozzle and clearly demonstrated that SANS can be extended to systems with particle volume fractions less than $10^{-6}$. The use of SAXS for incipient soot diagnostics has also been reported [15].

The principal advantage of SANS over light extinction and light scattering is that the wavelength $\lambda$ of neutrons in a typical SANS experiment $(0.5$ to $2.0 \mathrm{~nm}$ ) is smaller than the primary soot particle size.
Thus, the small-angle scattering pattern has structure, and we can estimate the size distribution parameters by fitting the observed scattering spectrum. Furthermore, neutron scattering stems primarily from the interaction of neutrons with atomic nuclei [16], so interpreting the SANS spectra requires only the basic physical properties of the particles (mass density and atomic composition), rather than less well-known quantities, such as the complex refractive index of incipient soot. Moreover, multiple scattering of a neutron by the soot is negligible [13,17], because the volume fraction found in sooting flames is typically of the order of $10^{-6}$. Finally, the low flux of neutrons does not perturb the incipient soot particles, unlike the ablation due to laser heating that can occur in LII [18].

In the present study, we demonstrate, for the first time, that SANS provides quantitative, in situ, spatially resolved information on soot formed in combustion flames. We studied two burner-stabilized, laminar premixed, ethylene flames, with different equivalence ratios of the unburned mixture to show that SANS can resolve the size distribution functions for particles with radii in the range of several nanometers and larger. Further analysis helped to define the lower size limit of detectable particles for the current experiments.

\section{Theory}

Irradiating an aerosol sample, such as the soot generated in a burner stabilized flame (Fig. 1), with cold neutrons scatters a small portion of the incident 


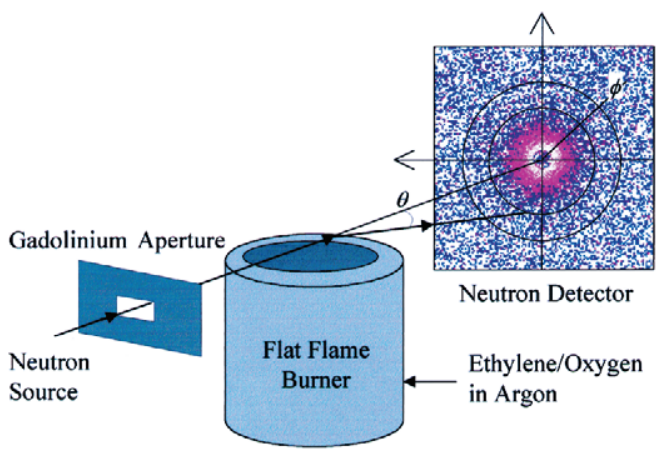

FIG. 1. A schematic of the experimental setup.

neutrons [17]. The coherent component of the neutron scattering intensity for a dilute aerosol sample is given by

$$
I(q)=\int_{r} N(r) P(q, r) d r
$$

where $r$ is the particle radius, $N(r)$ is the particle size distribution function (PSDF), $q$ is the magnitude of the momentum transfer vector, and $P(q, r)$ is the particle form factor $[17,19]$. Equation 1 relies on the first Born approximation; that is, it neglects multiple scattering by a single neutron, a condition that is easily met by flame soot even if it is optically dense. Because the particle velocity $(10-100 \mathrm{~cm} / \mathrm{s})$ is much less than the incident neutron velocity $\left(5 \times 10^{4}-\right.$ $8 \times 10^{4} \mathrm{~cm} / \mathrm{s}$ in the present study), the momentum transfer vector $q$ is a simple function of the neutron wavelength $\lambda$ and the scattering angle $\theta$ (Fig. 1),

$$
q=(4 \pi / \lambda) \sin (\theta / 2) .
$$

For spherical particles of uniform composition, the particle form factor depends on the particle radius and the momentum transfer vector $[17,20]$,

$$
P(q, r)=\left[4 \pi \rho_{b}(\sin q r-q r \cos q r)\right]^{2} / q^{6}
$$

where $\rho_{b}$ is the coherent scattering length density of the particle. For homogeneous particles, the scattering length density is given by $\rho_{b}=\Sigma_{j} b_{j} \rho_{j}$, where $\rho_{j}$ and $b_{j}$ are the number density and the bound coherent scattering length of type $j$ nuclei, respectively. We assume that soot particles contain only carbon $\left(b_{\mathrm{C}}=6.646 \times 10^{-13} \mathrm{~cm}\right)$ and hydrogen $\left(b_{\mathrm{H}}=\right.$ $-3.739 \times 10^{-13} \mathrm{~cm}$ ) so that

$$
\rho_{b}=\rho_{\mathrm{s}} \frac{b_{\mathrm{C}}+b_{\mathrm{H}} / \gamma}{m_{\mathrm{C}}+m_{\mathrm{H}} / \gamma}
$$

In equation $4, \gamma$ is the atomic C-to- $\mathrm{H}$ ratio, $\rho_{\mathrm{s}}$ is the mass density of a soot particle, and $m_{\mathrm{C}}$ and $m_{\mathrm{H}}$ are the atomic mass of carbon and hydrogen, respectively. Typically, $\gamma=5-8$ and $\rho_{\mathrm{s}}=1.8 \mathrm{~g} / \mathrm{cm}^{3}[21]$.

\section{Experiment and Facilities}

Atmospheric, laminar premixed, flat flames were stabilized on a water-cooled porous plug burner that consists of an inner cylindrical chamber, $5.08 \mathrm{~cm}$ in diameter, and an outer concentric annulus for shroud argon. The burner is similar to that described by Eng et al. [22] and Harris et al. [23]. The reactant mixture consists of ethylene, oxygen, and argon and is metered by sonic nozzles. The ethylene and oxygen were grade 5 , supplied by Matheson without further purification, and the argon was drawn from a high-pressure liquid argon Dewar. The flame temperature was measured with a $125 \mu \mathrm{m} \mathrm{Pt} / \mathrm{Pt} / 10 \%$ $\mathrm{Rh}$ (type S) thermocouple, coated with an $\mathrm{YCl}_{3} / \mathrm{BeO}$ mixture [24] and corrected for radiation effects [25].

SANS experiments were conducted using the NG7-SANS instrument at the Center for Neutron Research, the National Institute of Standards and Technology (NIST). The burner was housed in an argon-purged chamber with its exhaust manifold placed directly above the flame to prevent particles

TABLE 1

Flame conditions

\begin{tabular}{lccccccc}
\hline \multicolumn{9}{c}{$\begin{array}{c}\text { Unburned gas } \\
\text { composition }\end{array}$} & & & & \\
Flame & $\mathrm{C}_{2} \mathrm{H}_{4}$ & $\mathrm{O}_{2}$ & $\mathrm{Ar}$ & $\begin{array}{c}\text { Equivalence } \\
\text { ratio }\end{array}$ & $\begin{array}{c}\text { Linear velocity } \\
(\mathrm{cm} / \mathrm{s})\end{array}$ & $\begin{array}{c}\text { Maximum flame } \\
\text { temperature, } T_{\mathrm{m}}(\mathrm{K})\end{array}$ & $\begin{array}{c}\text { Burner temperature }^{\mathrm{c}} \\
(\mathrm{K})\end{array}$ \\
\hline $\mathrm{A}$ & 0.141 & 0.170 & 0.689 & 2.50 & 7.80 & 1698 & 333 \\
$\mathrm{~B}$ & 0.147 & 0.165 & 0.688 & 2.66 & 7.80 & 1677 & 328 \\
$\mathrm{C}$ & 0.115 & 0.197 & 0.688 & 1.75 & 8.22 & 1787 & 389 \\
$\mathrm{D}$ & 0.052 & 0.257 & 0.691 & 0.60 & 14.77 & 1757 & 424 \\
\hline
\end{tabular}

\footnotetext{
${ }^{\text {a }}$ Mole fractions.

${ }^{\mathrm{b}}$ Under the STP condition.

${ }^{\mathrm{c}}$ Measured on the centerline of the burner and $0.3 \mathrm{~cm}$ beneath the burner surface.
} 

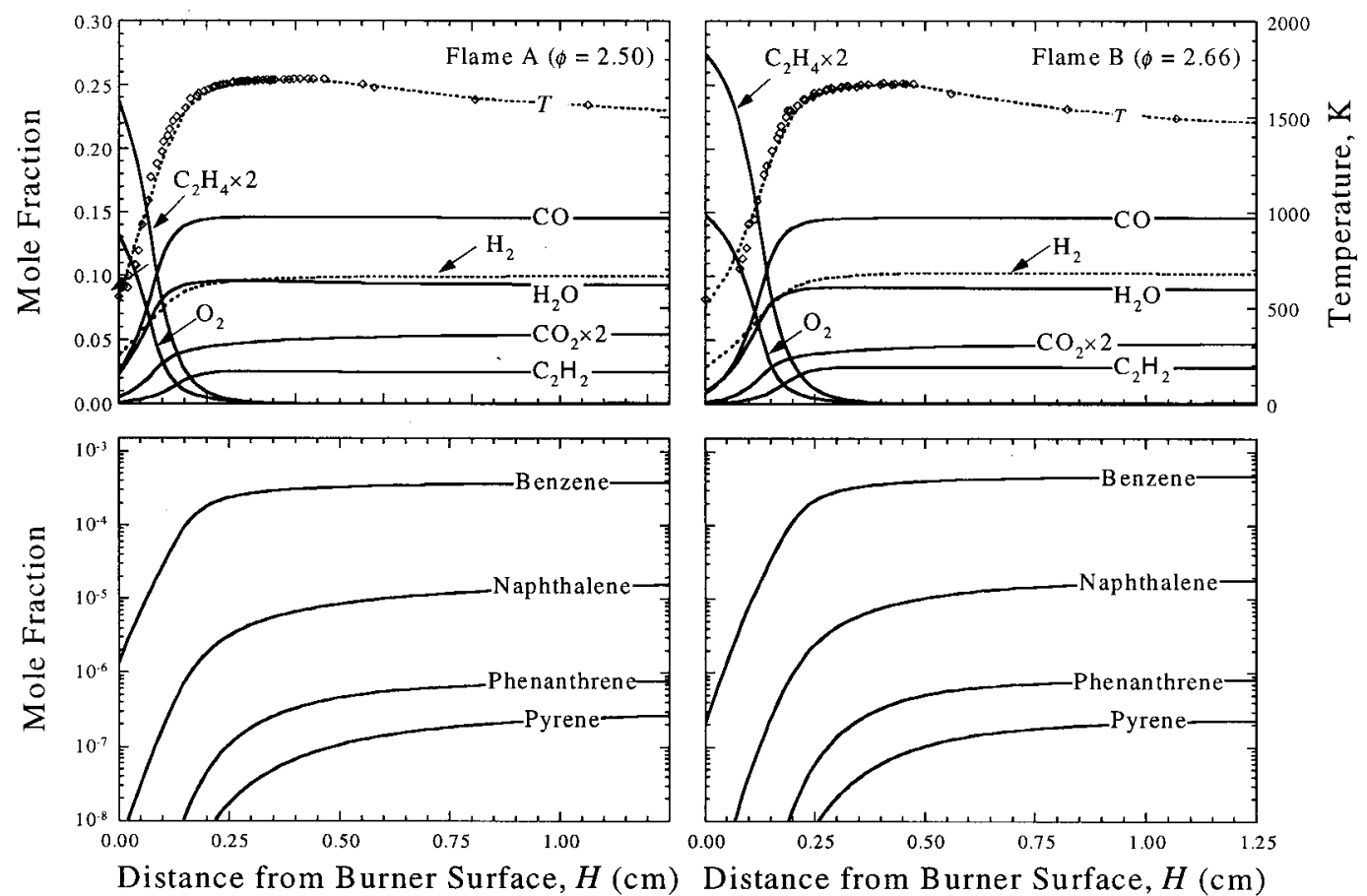

FIG. 2. The measured temperature profiles and the computed mole fraction profiles of the major gas-phase species and selected aromatic species for flame A (left) and flame B (right).

from entering into the neutron path outside of the sampling area. As illustrated in Fig. 1, the flame was positioned directly in the path of the neutron beam. A $1.2 \mathrm{~cm}$ wide and $0.4 \mathrm{~cm}$ high gadolinium aperture placed $20 \mathrm{~cm}$ from the center of the burner defined the sample volume. Due to beam divergence, the actual sampling volume at the centerline of the flame was about $1.36 \mathrm{~cm}$ wide and $0.56 \mathrm{~cm}$ high. In principle, better spatial resolution is possible by using a smaller aperture and moving it closer to the sample, but these options were not pursued in this preliminary study. Even better spatial resolution can be achieved by using a stronger neutron beam source readily available at the NIST facility. The scattered neutrons were detected on a two-dimensional detector at a sample-to-detector distance of $375 \mathrm{~cm}$. Two neutron wavelengths, $\lambda=0.5$ and $0.8 \mathrm{~nm}$, were used to extend the accessible $q$ range. To maximize the neutron flux we used a wavelength spread $\Delta \lambda / \lambda$ of $22 \%$.

At each wavelength the absolute neutron flux calibration was obtained by measuring the attenuated neutron flux reaching the detector during a beam center determination. Total sample integration times were typically $1 \mathrm{~h}$ per flame position at each wavelength. We also measured the scattering from the argon-purged sample chamber regularly to ensure that the background remained stable. At each wavelength, we collected up to $8 \mathrm{~h}$ of background without observing any changes. After subtracting the background signal of the Ar-purged chamber, and correcting for differences in pixel response, the twodimensional data were averaged over the circular angle $\phi$ (see Fig. 1) using the standard NIST data reduction package [26] to produce the $I(q)$ scattering spectrum.

We investigated four flame conditions, as summarized in Table 1. Flames A and B are sooting flames with identical linear velocities but different equivalence ratios $(\phi=2.50$ for flame $\mathrm{A}$ and 2.66 for flame B). To follow the evolution of the soot, we measured the neutron scattering spectra at six flame positions for each flame, with the center of the sample viewing volume positioned from $H=0.5 \mathrm{~cm}$ to $1.6 \mathrm{~cm}$ above the burner surface. To quantify the contribution of gas-phase species in the flame to the overall neutron scattering signal from the sooting flame, we characterized two non-sooting flames, flame $\mathrm{C}(\phi=1.75)$ and flame $\mathrm{D}(\phi=0.6)$ at $H=$ $1.0 \mathrm{~cm}$ above the burner surface.

Soot particles were collected in the exhaust manifold directly above the flame and analyzed (Desert Analytics). The soot contained only carbon and hydrogen with a carbon-to-hydrogen ratio of $\gamma=5.5$ \pm 0.1 , a value consistent with the ratio for mature soot particles measured in similar ethylene flames [21]. 

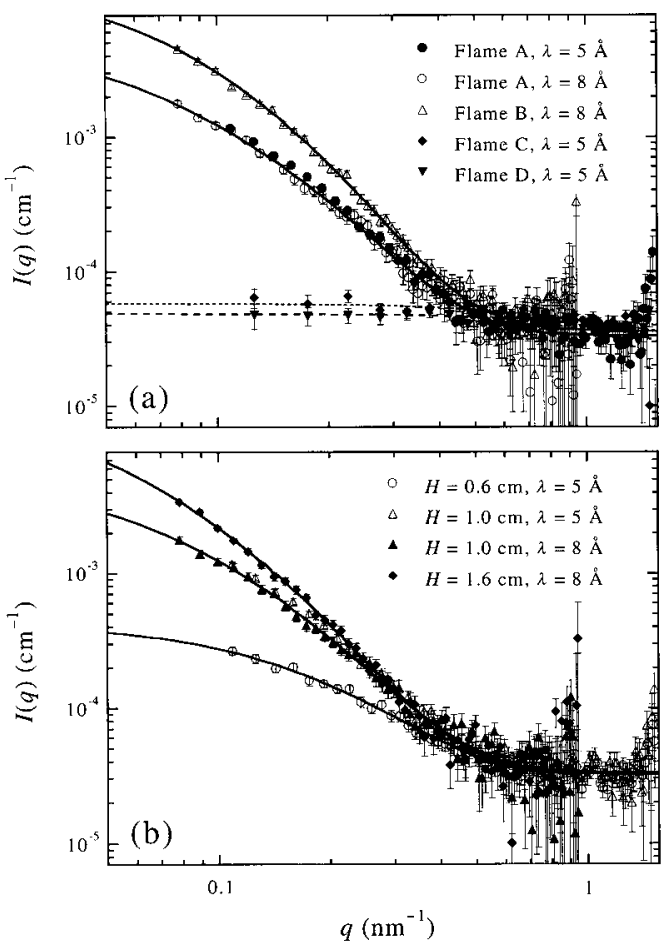

Fig. 3. The scattering spectra for measurements made (a) at a distance of $1.0 \mathrm{~cm}$ from the burner surface for flames A-D and (b) for flame A at several distances. The symbols are experimental data and the lines are obtained from the best $\chi^{2}$ fits (see equation 5 and text).

\section{Data Analysis}

The parameters of the particle size distribution are obtained by fitting the experimental spectra in the following way. We first calculate $I_{\mathrm{s}, \mathrm{coh}}$, the synthetic coherent scattering intensity, assuming a particle size distribution and average particle composition. We then minimize the $\chi^{2}$ quantity

$$
\chi^{2}=\sum_{i=1}^{n} \frac{\left[I_{\mathrm{s}, \mathrm{coh}}\left(q_{i}\right)+I_{\mathrm{s}, \mathrm{inc}}-I\left(q_{i}\right)\right]^{2}}{\sigma^{2}\left(q_{i}\right)}
$$

with respect to the parameters of the size distribution function and an additional incoherent scattering intensity, $I_{\mathrm{s}, \text { inc }}$ that accounts for scattering from the gases in the flame. In equation 5 , the $I\left(q_{i}\right)$ are the experimental data points, $\sigma\left(q_{i}\right)$ is the standard deviation of $I\left(q_{i}\right)$, and $n$ is the number of data points.

\section{Flame Simulation}

Direct measurement of gas-phase species concentration profiles is beyond the scope of the present study, so we simulated the flames using the PREMIX code $[27,28]$. The flame chemistry includes a detailed reaction mechanism of ethylene and acetylene combustion and aromatics formation [29]. The measured temperature profiles were used in the computation.

\section{Results and Discussion}

The structures of flames A and B, shown in Fig. 2 , are qualitatively the same, although flame B is expected to be sootier than flame A because of its higher equivalence ratio. The maximum temperature measured for flame A was $1698 \mathrm{~K}$, which is about $20 \mathrm{~K}$ higher than that measured for flame B. We observed visually that soot luminosity appears at $\sim 0.3$ and $\sim 0.4 \mathrm{~cm}$ above the burner surface, respectively, in flames A and B. These observations correlate well with the location where both the fuel and the oxidizer are predicted to disappear and the polycyclic aromatic hydrocarbon (PAH) concentrations rise sharply.

Typical background corrected scattering spectra are presented in Figs. 3a and 3b. Fig. 3a compares the scattering intensities for flames A-D at a position $H=1.0 \mathrm{~cm}$ above the burner surface. As expected, the scattering intensity measured from flame B lies distinctly above that from flame A, consistent with heavier sooting in flame B than in flame A. For flame $\mathrm{A}$, the scattering curves at $\lambda=0.5$ and $0.8 \mathrm{~nm}$ overlap nicely at $H=1.0 \mathrm{~cm}$, and this was the case for all of the experiments in which spectra were taken at two wavelengths. When $q<0.4 \mathrm{~nm}^{-1}$, the scattering spectra from the sooting flames (A and B) rise rapidly above the spectra from the non-sooting flames C and D whose spectra are essentially independent of $q$, as we would expect for incoherent scattering by gaseous species in the flames. At high $q\left(>0.4 \mathrm{~nm}^{-1}\right)$, all spectra approach a constant value for $I_{\text {s.inc }}$ of 3 to $4 \times 10^{-5} \mathrm{~cm}^{-1}$. Our calculations showed that this intensity was completely consistent with the level of incoherent scattering by water vapor and, to a lesser extent, by molecular hydrogen. For the sooting flames, we believe that this is still primarily due to scattering from gaseous species in the flame although, as discussed below, particles with radii less than $4 \mathrm{~nm}$ can also contribute.

In Fig. 3b, we demonstrate that spatially resolved SANS measurements can be made in flames. In particular, at low $q$, the scattering intensity from soot at $H=1.6 \mathrm{~cm}$ is more than one order of magnitude larger than at $H=0.6 \mathrm{~cm}$. This difference is primarily due to an increase in average particle size as the soot grows from $H=0.6$ to $1.6 \mathrm{~cm}$. At intermediate positions, the spectra changed in a continuous manner between the two extreme values shown in Fig. 3b.

Although the measured scattering intensities are well above background and change in a physically 


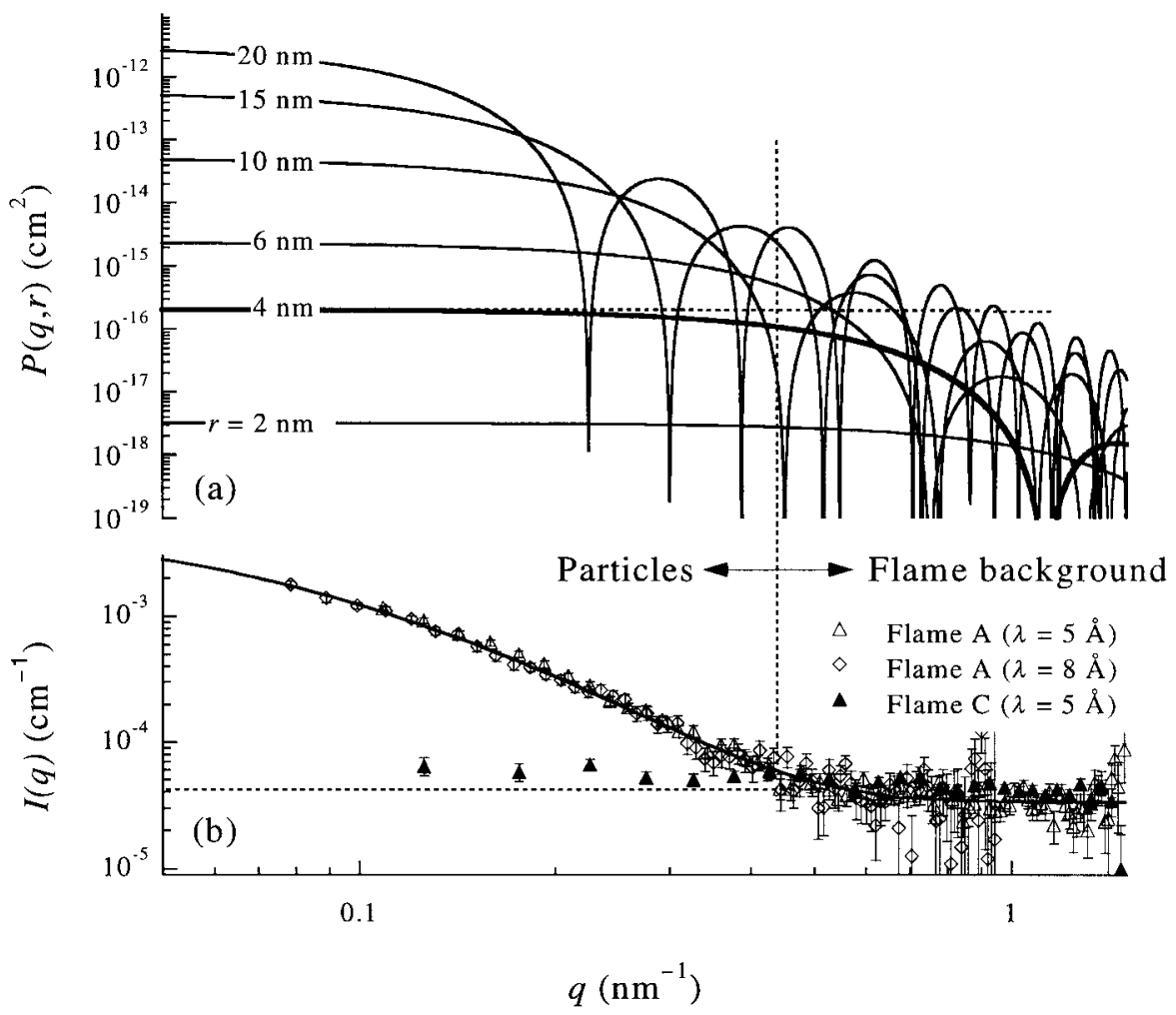

FIG. 4. (a) The variation of the form factor as a function of the momentum transfer vector, $q$, and the particle radius, $r$, compared to (b) the scattering intensity of flame A at $1.0 \mathrm{~cm}$ above the burner surface.

consistent manner, scattering from the gaseous compounds in the flame complicates the process of extracting the size distribution parameters for the soot particles. In general, the scattering intensity at low $q$ is due to the large particles, while information about the smaller particle comes from the scattering intensity at large $q$. To illustrate this dependence quantitatively, Fig. 4a shows how the form factor $P(q, r)$ varies as a function of particle radius for $2<$ $r<20 \mathrm{~nm}$. Fig. 4b, in turn, presents typical scattering spectra for both a sooting (flame A) and a nonsooting flame (flame C). By comparing Figs. 4a and $4 \mathrm{~b}$, we see that to extract quantitative information about particles with radii $<4 \mathrm{~nm}$, we need to be able to observe changes in the scattering spectrum in the region $q>0.4 \mathrm{~nm}^{-1}$. Unfortunately, as demonstrated by the non-sooting flame, in this $q$-range incoherent scattering from the gas-phase species overwhelms the scattering intensity. We therefore chose to impose a cutoff radius of $4 \mathrm{~nm}$ in all of our subsequent data analysis to separate our estimates of particle size from our estimates for gas-phase scattering. This approach is valid as long as the number density of particles with $r<4 \mathrm{~nm}$ is smaller than $I_{\mathrm{s}, \text { inc }} / P(q, r)$. In our case, the number density of $1-$ $2 \mathrm{~nm}$ particles would have to be greater than
$10^{13} \mathrm{~cm}^{-3}$ before these particles would contribute significantly to the scattering spectrum. For different flames, the cutoff radius may vary, depending on the water vapor and molecular hydrogen concentrations in the flame.

In fact, the specification of a cutoff radius demonstrates an added advantage of the SANS technique, compared to the light extinction and scattering method. That is, a lower particle size limit can be uniquely defined in SANS experiments. Furthermore, it is possible to eliminate incoherent scattering by using a deuterated fuel. Unlike hydrogen, deuterium does not generate incoherent scattering, and at the same time, it gives a large coherent scattering intensity. Using deuterium, it is possible to remove the cutoff radius and explore the size evolution of particles smaller than $4 \mathrm{~nm}$.

To estimate the size distribution parameters for the soot formed in flames A and B, we performed a weighted least squares fit of the data assuming that the PSDF in the sampling volume is given by

$$
N(r)=\frac{a}{b r} e^{-(1 / 2)[(\ln (r / c)) / b]^{2}} \text { for } r \geq 4 \mathrm{~nm}
$$

where $a, b$, and $c$ are the parameters of the size distribution. Because the distribution is truncated, they 
TABLE 2

Parameters estimated for the particle size distribution function (equation 6) and the incoherent component of the scattering intensity ${ }^{\text {a }}$

\begin{tabular}{|c|c|c|c|c|c|}
\hline$H(\mathrm{~cm})$ & $\lambda(\mathrm{nm})$ & $a \times 10^{11}\left(\mathrm{~cm}^{-4}\right)$ & $b$ & $c(\mathrm{~nm})$ & $I_{\mathrm{s}, \text { inc }} \times 10^{5}\left(\mathrm{~cm}^{-1}\right)$ \\
\hline \multicolumn{6}{|c|}{$\langle$ Flame A $\rangle$} \\
\hline 0.6 & 0.5 & $11.1(+0.6 /-1.1)$ & $0.63 \pm 0.05$ & $1.14 \pm 0.17$ & $3.20 \pm 0.16$ \\
\hline 0.7 & 0.5 & $14.9(+1.8 /-0.5)$ & $0.69 \pm 0.06$ & $1.00 \pm 0.17$ & $3.20 \pm 0.23$ \\
\hline 0.8 & 0.5 & $4.3(+0.3 /-0.2)$ & $0.70 \pm 0.05$ & $1.41 \pm 0.19$ & $3.25 \pm 0.21$ \\
\hline 0.8 & 0.8 & $4.7(+0.5 /-0.2)$ & $0.70 \pm 0.05$ & $1.36 \pm 0.17$ & $3.23 \pm 0.63$ \\
\hline 0.8 & 0.5 and 0.8 & $2.6(+0.3 /-0.0)$ & $0.65 \pm 0.05$ & $1.81 \pm 0.19$ & $3.25 \pm 0.30$ \\
\hline 1.0 & 0.5 & $0.6(+0.0 /-0.0)$ & $0.54 \pm 0.04$ & $3.61 \pm 0.25$ & $3.42 \pm 0.24$ \\
\hline 1.0 & 0.8 & $3.4(+0.2 /-0.2)$ & $0.72 \pm 0.04$ & $1.50 \pm 0.15$ & $3.31 \pm 0.53$ \\
\hline 1.0 & 0.5 and 0.8 & $0.8(+0.0 /-0.1)$ & $0.58 \pm 0.04$ & $3.01 \pm 0.21$ & $3.42 \pm 0.30$ \\
\hline 1.2 & 0.8 & $1.7(+0.2 /-0.0)$ & $0.71 \pm 0.05$ & $1.98 \pm 0.26$ & $3.50 \pm 0.89$ \\
\hline 1.6 & 0.8 & $1.2(+0.1 /-0.0)$ & $0.73 \pm 0.05$ & $2.18 \pm 0.28$ & $3.27 \pm 0.09$ \\
\hline \multicolumn{6}{|c|}{$\langle$ Flame B $\rangle$} \\
\hline 0.5 & 0.8 & $4.3(+0.4 /-0.5)$ & $0.72 \pm 0.07$ & $1.15 \pm 0.21$ & $4.05 \pm 0.54$ \\
\hline 0.6 & 0.5 & $0.8(+0.1 /-0.0)$ & $0.51 \pm 0.04$ & $3.27 \pm 0.25$ & $3.41 \pm 0.24$ \\
\hline 0.6 & 0.8 & $3.3(+0.3 /-0.1)$ & $0.67 \pm 0.04$ & $1.58 \pm 0.16$ & $3.65 \pm 0.51$ \\
\hline 0.6 & 0.5 and 0.8 & $2.2(+0.1 /-0.2)$ & $0.61 \pm 0.03$ & $2.03 \pm 0.14$ & $3.43 \pm 0.22$ \\
\hline 0.7 & 0.5 & $1.1(+0.1 /-0.0)$ & $0.58 \pm 0.03$ & $2.93 \pm 0.18$ & $3.41 \pm 0.21$ \\
\hline 0.7 & 0.8 & $6.6(+0.5 /-0.2)$ & $0.74 \pm 0.03$ & $1.24 \pm 0.11$ & $3.49 \pm 0.56$ \\
\hline 0.7 & 0.5 and 0.8 & $1.5(+0.0 /-0.1)$ & $0.60 \pm 0.03$ & $2.55 \pm 0.14$ & $3.43 \pm 0.27$ \\
\hline 0.8 & 0.8 & $1.4(+0.2 /-0.0)$ & $0.62 \pm 0.04$ & $2.72 \pm 0.25$ & $3.39 \pm 0.94$ \\
\hline 1.0 & 0.8 & $0.9(+0.1 /-0.0)$ & $0.62 \pm 0.04$ & $3.31 \pm 0.25$ & $3.57 \pm 0.89$ \\
\hline 1.6 & 0.8 & $0.4(+0.0 /-0.0)$ & $0.57 \pm 0.03$ & $5.05 \pm 0.28$ & $3.46 \pm 0.73$ \\
\hline
\end{tabular}

a The errors represent the $95 \%$ confidence limit in the parameters.

do not correspond directly to the number density, the dispersity, and the medium radius of a lognormal distribution function. The $\chi^{2}$ minimization (i.e., equation 5) returns estimates of the parameters $a, b, c$, and $I_{\mathrm{s} \text {,inc }}$, and high-quality fits were obtained for all of the scattering spectra. Table 2 shows the parameters from the best fits at each location $H$ of the flames. Representative fits are presented as the solid lines in Fig. 3. In all cases, the optimal $\chi^{2}$ values were found to be about equal to the number of data points $n$ in equation 5 , indicating that the fits are at or within the experimental uncertainty of $I(q)$.

To confirm that the minimization converges to a unique minimum point in the parameter space, we present typical contour plots of $\chi^{2}$ above its minimum (Fig. 5). Because $b$ and $c$ determine the shape of the scattering spectra, while $a$ and $I_{\mathrm{s} \text {,inc }}$ determine the intensity, the uncertainty spaces of parameters $b$ and $c$ can be decoupled from those of $a$ and $I_{\text {s,inc. }}$. The closure of the contours indicates that the best fit, denoted by the symbols in Fig. 5, is indeed a global minimum in the parameter space. These contour plots also form the basis of error analysis where we determine the error limits by the $95 \%$ confidence limit space. These error limits are presented in Table 2 .
In all our experiments, the incoherent scattering

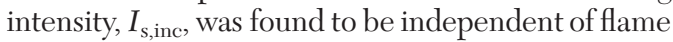
condition and flame location. Averaged over all spatial locations in the two flames, the mean value of $I_{\mathrm{s} \text {,inc }}$ was $\overline{\mathrm{I}}_{\mathrm{s} \text {,inc }}=(3.4 \pm 0.4) \times 10^{-5} \mathrm{~cm}^{-1}$, where the error represents two standard deviations at $95 \%$ confidence. The magnitude of $\overline{\mathrm{I}}_{\mathrm{s} \text {,inc }}$ and the fact that it is invariant are consistent with our interpretation that the incoherent scattering is due to the gases in the flames.

The mean properties of the particle size distribution were calculated using equation 6 and the parameters obtained from the $\chi^{2}$ minimization. Minor corrections were made to the mean properties due to a minor convergence of the flame above the burner surface. Fig. 6 presents the soot volume fraction $f_{\mathrm{v}}=$ $(4 / 3) \pi N\left\langle r^{3}\right\rangle$, the sixth moment $N\left\langle r^{6}\right\rangle$, the total number density $N$ for $r \geq 4 \mathrm{~nm}$, and the mean radius $\langle r\rangle$ as a function of the distance from the burner surface. The error bars were obtained from an error analysis employing 25,000 random points in the parameter space that represent a $95 \%$ confidence limit. As expected, the volume fraction, $N\left\langle r^{6}\right\rangle$, and the mean radius increase with distance above the burner surface. The increase in the soot volume fraction is 

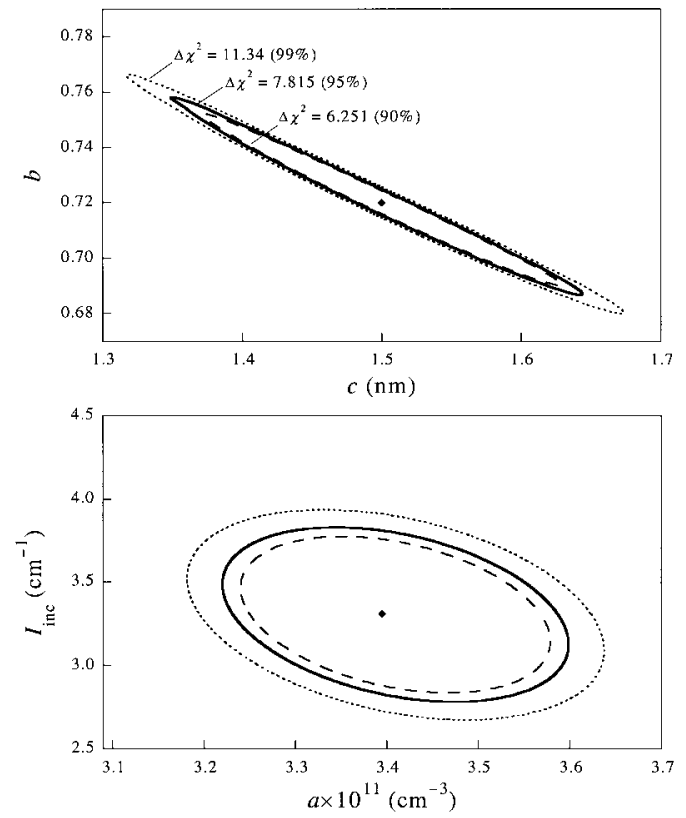

FIG. 5. Contour plots of the confidence regions near the minimum- $\chi^{2}$ point (symbols, $\chi_{\min }^{2}=69.935$ ), obtained for the SANS experiment using flame A and $H=1.0 \mathrm{~cm}$. The $\Delta \chi^{2}$ values of $6.251,7.815$, and 11.34 represent the 90,95 , and $99 \%$ confidence limits of the parameter space.

primarily a result of increases in particle size. Because of the higher equivalence ratio, flame $\mathrm{B}$ is sootier than flame A, so the volume fraction, $N\left\langle r^{6}\right\rangle$, and the mean radius of flame B are consistently larger than their counterparts of flame A. The total number density is about $10^{11} \mathrm{~cm}^{-3}$ for both flames and is quite insensitive to position in the flame, perhaps because it represents an average over a rather large vertical distance in the flame. The lack of variation in the number density could also mean that the decrease in particle number due to particle coagulation is balanced by new particles entering the $4 \mathrm{~nm}$ radius size class because of continued nucleation and growth. Since the computed PAH profiles, given in the bottom panels of Fig. 2, show that the soot precursor concentrations remain constant well into the postflame region, continued particle production is a distinct possibility.

Our data analysis may have been affected uncertainties in the soot material properties, a problem that is also encountered in light extinction and scattering measurements. If the mass density and the C-to- $\mathrm{H}$ ratio of the soot are independent of particle size, uncertainties in these quantities only affect the scattering length density (equation 5) and thus the total number density of the soot. If we assume that the mass density of soot is that of solid pyrene $\left(1.3 \mathrm{~g} / \mathrm{cm}^{3}\right)$, the true number density is a factor of
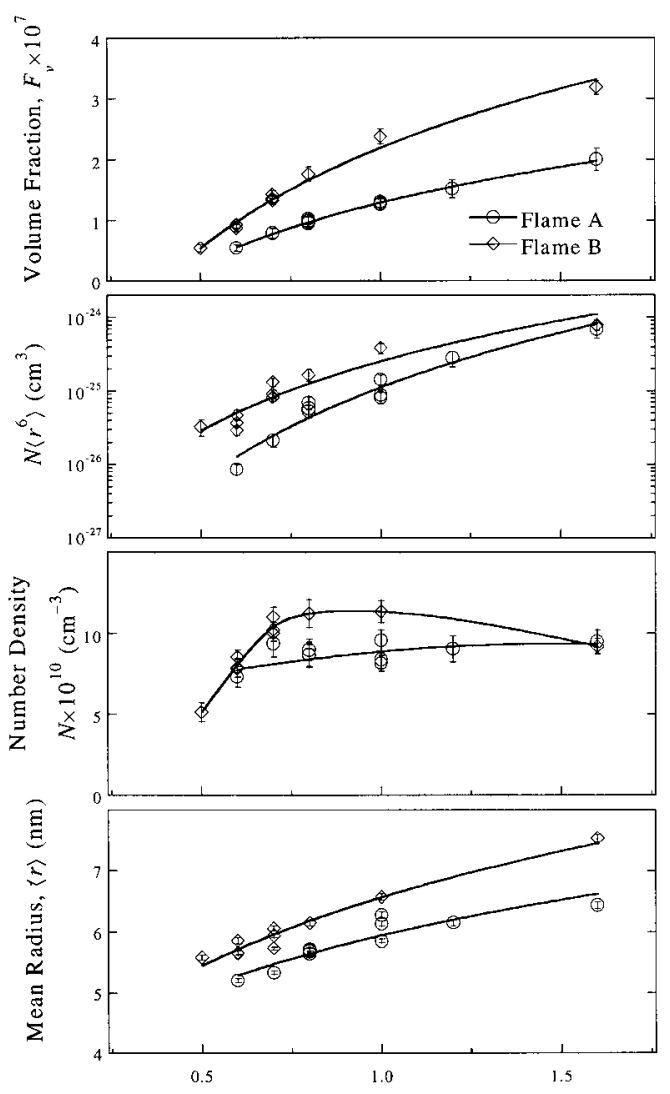

Distance from Burner Surface, $H(\mathrm{~cm})$

FIG. 6. The volume fraction, $N\left\langle r^{6}\right\rangle$, number density, and mean radius of soot particles having radii larger than $4 \mathrm{~nm}$, measured for flame A (circles) and flame B (diamonds). The lines are fits to the data. The error bars represent two standard deviations and are described in more detail in the text.

1.9 higher than that shown in Fig. 6. For young soot particles, the C-to-H ratio could be as low as 2 [21]. The particle number density at this C-to-H ratio would increase by a factor of 1.7. Taking the extreme case that $\rho_{\mathrm{s}}=1.3 \mathrm{~g} / \mathrm{cm}^{3}$ and $\gamma=2$, the number density would increase by a factor of 3 . The reduced moments of the PSDF remain unaffected.

In Figs. 3 and 6, the data at each sampling position represent an average over $\Delta H=\sim 0.56 \mathrm{~cm}$, and so they are not point measurements. Yet, because the spectra can be predicted as part of a flame simulation and exhibit strong spatial variation, these data place rather strong constraints on available models of soot nucleation and growth.

The results of the present study suggest that a further advantage of SANS for the study of flame soot may be its ability to sample optically thick flames. The current flames have a neutron transmission over 
$99 \%$. Therefore, the probability of a single neutron scattered by multiple particles is smaller than $0.01 \%$ over the sampling length. Given this probability, it may be possible to achieve quantitative measurements for extremely sooty flames.

\section{Conclusion}

We demonstrated, for the first time, that SANS can be used to extract detailed, spatially resolved information about the particle size distribution function of soot formed in one-dimensional laminar premixed flames. We determined the mean properties of the particle size distribution in two ethylene flames and found that they were consistent with our basic understanding of soot formation in these flames. Scattering at $q>0.4 \mathrm{~nm}^{-1}$ was dominated by gaseous components of the flame that interfere with the scattering signals from extremely small particles. Nonetheless, the lower particle size limit can be uniquely defined, given the level of flame background scattering.

\section{Acknowledgments}

We thank Dr. J. Barker and Dr. C. Glinka of NIST for their help and for useful discussions. This work was supported by the National Science Foundation CHE-0089136. The work was based on activities supported by the National Science Foundation under agreement No. DMR-9986442.

\section{REFERENCES}

1. Haynes, B. S., and Wagner, H. Gg., Prog. Energy Combust. Sci. 7:229-273 (1981).

2. Wagner, H. Gg., Hazardous Waste Hazardous Mater. 11:5-29 (1994).

3. Kennedy, I. M., Prog. Energy Combust. Sci. 23:95-132 (1997).

4. Richter, H., and Howard, J. B., Prog. Energy Combust. Sci. 26:565-608 (2000).

5. D'Alessio, A., in Particulate Carbon-Formation During Combustion (D. C. Siegla and G. W. Smith, eds.), Plenum, New York, 1982, pp. 207-259.

6. Dec, J. E., Zue Loye, A. O., and Siebers, D. L., SAE technical paper 91-0224.
7. Quay, B., Lee, T.-W., Ni, T., and Santoro, R. J., Combust. Flame 97:384-397 (1994).

8. Vander Wal, R. L., and Weiland, K. J., J. Appl. Phys. B 59:445-452 (1994).

9. Stuhrmann, H. B., Haas, J., Ibel, K., Dewoif, B., Koch, M. H. J., and Crichton, R. R., Proc. Natl. Acad. Sci. U.S.A. 73:2379-2383 (1976).

10. Kotlarchyk, M., Chen, S. H., Huang, J. S., and Kim, M. W., Phys. Rev. A 29:2054-2069 (1984).

11. Wiegand, W., and Ruland, W., Prog. Colloid Polym. Sci. 66:355-366 (1979).

12. Mortensen, K., J. Phys.: Condens. Matter 8:103-124 (1996).

13. Wyslouzil, B. E., Cheung, J. L., Wilemski, G., and Strey, R., Phys. Rev. Lett. 79:431-434 (1997).

14. Wyslouzil, B. E., Wilemski, G., Cheung, J. L., Strey, R., and Barker, J., Phys. Rev. E 60:4330-4335 (1999).

15. Hessler, J. P., Seifert, S., Winans, R. E., and Fletcher, T. H., Faraday Discuss. 199:395-407 (2002).

16. Price, D. L., and Sköld, K., in Methods in Experimental Physics, Vol. 23 (K. Sköld and D. L. Price, eds.), Academic Press, London, 1986, pp. 1-98.

17. Wilemski, G., Phys. Rev. E 61:557-564 (2000).

18. Vander Wal, R. L., Choi, M. Y., and Lee, K.-O., Combust. Flame 102:200-204 (1995).

19. Kotlarchyk, M., and Chen, S.-H., J. Chem. Phys. 79:2461-2469 (1983)

20. Glatter, O., and Kratky, O., Small Angle X-Ray Scattering, Academic Press, London, 1982.

21. Harris, S. J., and Weiner, A. M., Combust. Sci. Technol. 31:155-167 (1983).

22. Eng, J. A., Zhu, D. L., and Law, C. K., Combust. Flame 100:645-652 (1995).

23. Harris, S. J., Weiner, A. M., Blint, R. J., and Goldsmith, J. E. M., Proc. Combust. Inst. 21:1033 (1986).

24. Shandross, R. A., Longwell, J. P., and Howard, J. B., Combust. Flame 85:282-284 (1991).

25. Kaskan, W. E., Proc. Combust. Inst. 16:134-143 (1957).

26. SANS Data Reduction and Imaging Software, National Institute of Standards and Technology, Center for Neutron Research, 1999.

27. Kee, R. J., Rupley, F. M., and Miller, J. A., Sandia report SAND 89-8009B.

28. Kee, R. J., Grcar, J. F., Smooke, M. D., and Miller, J. A., Sandia report SAND85-8240 UC4.

29. Wang, H., and Frenklach, M., Combust. Flame 110:173-221 (1997).

Post-print standardized by MSL Academic Endeavors, the imprint of the Michael Schwartz Library at Cleveland State University, 2017. 